\title{
Antioxidant and Tissue-Protective Studies on Ajwa Extract: Dates from Al Madinah Al-Monwarah, Saudia Arabia
}

\author{
Ahmed R. Ragab ${ }^{1,5 *}$, Mohamed A. Elkablawy ${ }^{2,6}$, Basem Y. Sheik ${ }^{3}$ and Hany N. Baraka ${ }^{4}$ \\ ${ }^{1}$ Department of Forensic Medicine and Clinical Toxicology, Faculty of Medicine, Mansoura University, Egypt \\ ${ }^{2}$ Department of Pathology, Faculty of Medicine, Menoufyia University, Egypt and Taibah University, Kingdom of Saudi Arab \\ ${ }^{3}$ Department of Surgery, Faculty of Medicine, Taibah University, Kingdom of Saudi Arab \\ ${ }^{4}$ Department of Pharmacology, Faculty of Pharmacy, Mansoura University, Egypt \\ ${ }^{5}$ Dammam Regional Poison Control Center, Kingdom of Saudi Arab \\ ${ }^{6}$ Department of Pathology, Faculty of Medicine, Taibah University, Kingdom of Saudi Arab
}

\begin{abstract}
The objective was to study the in-vivo protective effect of Al-Madinah Ajwa (name of the most famous date in AlMadinah Al-Monwarah City) extract against lead acetate toxicity on the tissues of vital organs. Four rabbit groups were used as an animal model for this study. Ajwa extract treated group (300 mg/kg/day, for 14 days) were evaluated for lead acetate (500 ppm in drinking water for 14 days) intoxication compared to lead acetate alone-intoxicated group; Ajwa extract group and control group. This was done by assessment of liver and kidney functions, blood lead levels, levels of oxidants-antioxidants and histopathological changes in liver, kidney, heart and lung in different groups. The lead acetate intoxicated group showed significant elevation of serum glutamic pyruvic transaminase (SGPT), serum glutamic oxaloacetic transaminase (SGOT), alkaline phosphatase (ALP), total bilirubin (TB), serum creatinine-urea (Cr-U), lipid hydroperoxide (LPO), protein carbonyl content (PCC), and depression of Superoxide dismutase (SOD) and Glutathione peroxidase (GPX) levels as compared to control. The Agwa extract showed tissue protective effect by significant restoration of (SGPT), (SGOT), (ALP), (TB), (Cr-U) (LPO), (PCC), (SOD) and (GPX) levels compared to the previous group. The histopathological evaluation showed marked vascular congestion, interstitial hemorrhage, cellular degeneration and necrosis in different organs of lead acetate intoxicated group, while Agwa extract treated group showed mild congestion and slight focal cellular degeneration. Therefore, outcome of the present study validates the ameliorative and protective effects of Al-Madinah Ajwa dates against the toxic effects of lead acetate poisoning.
\end{abstract}

Keywords: Ajwa; Anti-oxidant; Toxicity; Lead acetate

\section{Introduction}

Lead $(\mathrm{Pb})$ is a toxic metal that induces a wide range of behavioral, biochemical and physiological effects in humans. Even though blood lead levels (BLL) continue to decline over the past two decades, specific populations like infants and young children are still at a higher-risk [1].

As lead exposure tends to be subacute, produces only subtle clinical symptoms. Chronic exposure cases are more common than acute toxicity. Lead via the gastro intestinal absorption is first taken up by the red blood cells and is distributed to all vascular organs [2]. Pathogenesis of lead poisoning is mainly attributed to lead- induced oxidative stress. Chronic lead exposure is known to disrupt the pro oxidant/antioxidant balance existing within the mammalian cells [3] Lead is reported to cause oxidative stress by generating the release of reactive oxygen species (ROS) such as superoxide radicals, hydrogen peroxide and hydroxyl radicals and lipid peroxides [4-6].

As oxidative stress has been mainly implicated in the lead toxicity, reducing the possibility of lead acetate interacting with cellular metabolism biomolecules and decreasing the reactive oxygen species generation by the use of antioxidant nutrients has been received a considerable attention in the recent past [3-7]. There has been increased interest among phytotherapy researchers to use medicinal plants with antioxidant activity for protection against heavy-metal toxicity.

Nutritional sciences had been expanding the knowledge of how food influence consumers in relation to specific health parameters, where high fruit and vegetable consumption was associated with a reduced risk of several chronic diseases such as cancer, cardiovascular disease, neurodegenerative disease and inflammation. [8] The compounds though to be responsible for the protective effects of a fruit and vegetables rich diet include carotenoids, anti-oxidants vitamins as Syzygium aromaticuum L. extracts and dates extracts (Phoenix dactlifera L.) $[9,10]$. In this regard, attention has been focused on the significance of phenolics such as phenolic acids, flavonoids, and in particular, anthocyanins [11].

All Date varieties serve as a good source of natural antioxidants and antimutagenic properties. Selenium prevents cancer and important to immune function, is also found in Dates. Also, Dates contain 23 types of amino acids and at least six vitamins, including a small amount of vitamin C and Vitamin B (1) thiamine, B (2) riboflavin, nicotine acid (niacin) and Vitamin A [8-10].

The history of Ajwa dates goes back to 5000 BC. Ajwa dates are a delightfully fruity and soft kind of dates that also have a fine texture. There are many benefits of Ajwa dates. It is only cultivated in Saudi Arabia/Al-Madinah Al-Monwarah. Most Consumers usually break their fasting period by consuming Ajwa dates. Ajwa dates contain high amounts of natural fiber, which is effective in aiding digestion. Ajwa dates are a good source of the mineral potassium. This essential

*Corresponding author: Ahmed R. Ragab, Department of Forensic Medicine and Clinical Toxicology, Faculty of Medicine, Mansoura University, Egypt, E-mail: ahmedrefat1973@yahoo.com

Received November 26, 2012; Accepted December 18, 2012; Published December 21, 2012

Citation: Ragab AR, Elkablawy MA, Sheik BY, Baraka HN (2013) Antioxidant and Tissue-Protective Studies on Ajwa Extract: Dates from Al Madinah Al-Monwarah, Saudia Arabia. J Environ Anal Toxicol 3:163. doi:10.4172/2161-0525.1000163

Copyright: ( 2013 Ragab AR, et al. This is an open-access article distributed under the terms of the Creative Commons Attribution License, which permits unrestricted use, distribution, and reproduction in any medium, provided the original author and source are credited. 
mineral is necessary for the maintenance of muscle contractions in the body. Individuals with constipation and other digestive problems may benefit from consuming Ajwa dates. It works through providing roughage to the body, which then stimulates the sluggish bowels and relieves constipation [11].

Ajwa dates are useful for lactating women because they assist in enriching breast milk. Furthermore, several studies have shown that kids of mothers who eat Ajwa dates regularly are less susceptible to diseases and infections. The other huge advantage of consuming Ajwa dates is that they comprise of high iron content. Iron is vital in RBC production and they may also assist to treat and prevent anemia [12].

The current study evaluates the impact of anti-lead toxic effect of Al-Madinah Ajwa (the name of the most famous date in Al-Madinah Al-Monwarah City) extract on oxidant-antioxidant status, hepatic, pulmonary and renal tissue changes through studied animal model to human disease.

\section{Materials and Methods}

\section{Materials}

Lead acetate (99.5\%) was purchased from Sigma Chemical Co. (St. Louis, MO, USA). Lipid hydroperoxide (LPO), protein carbonyl content (PCC), superoxide dismutase (SOD), glutathione peroxidase (GPX), glutathione S-transferase (GST) assay kits were purchased from Cayman Chemicals (Cayman Chemicals and Pierce Biotechnology, USA). Diagnostic kits, serum glutamic pyruvic transaminase (SGPT), serum glutamic oxaloacetic transaminase (SGOT), alkaline phosphatase (ALP), total bilirubin (TB) were purchased from Merck, Darmstadt, Germany. Pentothal sodium was acquired from Abbott Laboratories, KSA. All the chemicals were of analytical grade.

\section{Preparation of Ajwa extract}

Ajwa dates were bought from AL-Madinah Al-Monawarah Market and authenticated by a Pharmacogenist (Hany N. Baraka), Ajwa dates was dried under shades, cut into small pieces and then grinded. The coarse powder $(3500 \mathrm{gm})$ of the date was macerated in $2 \mathrm{~L}$ of ethanol for approximately 15-20 days with frequent shaking. The extract was filtered and marc left behind. The extract was concentrated under reduced pressure on Rotary evaporator until a semisolid residue was obtained. Mark was further extracted under the same conditions twice. The dark brown semisolid residue approximate yield was $2510.4 \mathrm{~g}$ [13]. The use of equivalent dates dose to rabbits was the daily amount of the human person, as cited by Miller et al. [14].

\section{Extraction of the phenolics}

The phenolics from palm date fruits were excreted as described in the mentioned literature [15]. A portion of $10 \mathrm{~g}$ of date fruit was extracted with $90 \mathrm{ml}$ of methanol (99\%), after mixing with magnetic stirrer for half an hour, and then filtered with filter paper Whatman No. 4. The remaining materials were re-extracted three times, and then concentrated by lyophilization until dryness.

\section{Determination of total phenols}

Total Phenol Content was determined according to the method described by Negi et al. [16].

\section{Determination of glycosides in dates}

Sugars were determined in dates according to AOAC method [17] by using HPLC (Shimadzu LC-10 Ad, Kyoto, Japan).

\section{Flavonoids and phenolic compound quantification}

The extraction and the separation of flavioindes were done according to Lunn [18]. The separations of individual phenols in extracts were carried out on shimaduz liquid chromatographic system. The chromatic peaks of phenols were confirmed by comparing their retention times and UV spectra with their reference standards.

\section{Thiobarbituric acid reactive substances (TBARS)}

Assessment of lipid oxidation was achieved by evaluation the formation of TBARS according to the method of Garcia-Alonso et al. [19]. The ability of the extract to inhibit the peroxidation was calculated using the following equation: Peroxidation inhibition $(\%)=($ Control 1 OD-sample OD/Control 1 OD)X100

\section{Animals and experimental design}

Healthy rabbits of either sex (local breed), weighing from 1.5-2.2 $\mathrm{kg}$ were purchased from a local market- Al-Madinah Al-MonwarahKSA. They were kept in the research laboratory of Faculty of Medicine, Taibah University -Al-Madinah Al-Monwarah-KSA. The animals were maintained under standard housing laboratory conditions, a relative humidity of $65 \%$ to $85 \%$, a temperature of $18-20^{\circ} \mathrm{C}, 12 \mathrm{~h} \mathrm{light/dark}$ cycles, and fed a standard pellet diet and water ad libitum. The rabbits were placed in polypropylene-metal cages with one animal per cage and were allowed to acclimatize for one week prior to treatment.

All the experimental protocols conducted on rabbits were performed in accordance with the internationally accepted principles for laboratory animal use and care and Institutional animal care and use committee, and the study got approval from the Research and Ethics committee (Taibah University).

Animals were divided randomly into four groups with ten animals in each group and five rabbits in the control group. Group 1: Control; Group 2: Rabbits exposed to lead acetate alone in drinking water (500 ppm) [20] (to clarify the toxic effects of lead acetate in the studied group); Groups 3: Received Ajwa extract alone (300 mg/kg b.w/d) [14] (to demonstrate the effect of Ajwa extract alone on biochemical and histological parameters of the studied animal group). Group 4: Rabbits exposed to lead acetate in drinking water and treated with Ajwa extract at the same dose daily for 14 days (to detect the antitoxic effects of Ajwa extract in lead intoxicated studied animal group). Ajwa extract was diluted with distilled water to the desired concentration of $300 \mathrm{mg} /$ $\mathrm{kg}$ body weight and was orally administrated to rabbit (two $\mathrm{ml} / \mathrm{rabbit} /$ day).

At the end of experimental period, rabbits were anaesthetized with intravenous administration of Pentothal sodium $(0.5 \mathrm{ml} / \mathrm{kg})$ and blood samples $(3 \mathrm{ml})$ from all the four groups were drawn. Serum was separated by centrifugation at $2500 \mathrm{rpm}$ for $15 \mathrm{~min}$ and used for the determination of (SGOT), (ALP), (TB), (Cr-U), (LPO), (PCC), (SOD), (GPX) and Glutathione S-transferase (GST). All biochemical parameters were assayed according to the standard procedures using ELISA kits (Cayman Chemicals and Pierce Biotechnology USA). Whereas, protein levels were estimated by protein assay kits from Cayman Chemicals (Cayman Chemicals and Pierce Biotechnology, USA). 


\section{Biochemical assessment}

Assessment of blood leads level: Blood lead levels were assayed by a graphite furnace atomic absorption spectrophotometry method.

Hepatic and renal biochemical estimations: Merck diagnostic kits and UV-VIS Spectrophotometer (U2020 IRMECO, Germany) were used to measure serum glutamate oxaloacetate transaminase (SGOT), serum glutamic pyrovate transaminase (SGPT), alkaline phosphatase (ALP), total bilirubin (TB), serum creatinine-urea (Cr-U).

Oxidants-antioxidant status assessment: Total antioxidant assay: Using the total antioxidant assay kit, aqueous and lipid soluble antioxidants were not separated and thus combined antioxidant activities of all its constituents were assessed. The assay relies on the ability of antioxidants in the sample to inhibit the oxidation of ABTS (2, 2'-Azino-di-[3-ethylbenzthiazoline sulphonate]) to $\mathrm{ABTS}^{\circledR} \bullet+$ by metmyoglobin. The amount of ABTS produced was monitored by reading the absorbance at $405 \mathrm{~nm}$.

Lipid hydroperoxide (LPO) assay: A quantitative extraction method as provided in the kit method for lipid hydroperoxide assay was used to extract lipid hydroperoxides into chloroform and the extract was directly used. This procedure eliminates any interference caused by hydrogen peroxide or endogenous ferric ions in the sample and provides a sensitive and reliable assay for lipid peroxidation. The absorbance was read at $500 \mathrm{~nm}$ using a 96 well plate spectrophotometric reader and a dose-response curve of the absorbance unit vs. concentration in nmol was generated.

Protein carbonyl content (PCC) assay: In the protein carbonyl content assay kit, protein samples are derivatized by making use of the reaction between 2, 4-dinitrophenylhydrazine (DNPH) and protein carbonyls. Formation of a Schiff base produces the corresponding hydrazone which was analyzed spectrophotometrically at 360-385 nm.

Superoxide dismutase (SOD) assay: This assay kit utilizes a tetrazolium salt for the detection of superoxide radicals $\left(\mathrm{O}_{2}^{-}\right)$generated by xanthine oxidase and hypoxanthine. One unit of SOD is defined as the amount of enzyme necessary to exhibit $50 \%$ dismutation of the superoxide radical. Oxidation rate of tetrazolium salt to formazan dye by $\mathrm{O}_{2}$ - is inversely proportional to the endogenous activity of SOD. The formazan dye stains, the wells and its staining intensity was detected by absorbance spectrophotometry at $450 \mathrm{~nm}$ using a plate reader.

Glutathione peroxidase (GPx) assay: This assay kit measured GPx activity indirectly by a coupled reaction with glutathione reductase. Oxidized glutathione, produced upon reduction of an organic hydroperoxide by GPx, is recycled to its reduced state by glutathione reductase and NADPH. The oxidation of NADPH to NADP+ is accompanied by a decrease in absorbance at $340 \mathrm{~nm}$. The rate of decrease in the absorbance at 340 was directly proportional to the GPx activity in the sample.

\section{Histopathological studies}

The rabbits from all groups were sacrificed after intravenous administration of pentothal sodium $(0.5 \mathrm{ml} / \mathrm{kg})$. Tissues were obtained for histological assessment from liver, kidney, heart and lung. Formalin fixed, paraffin embedded blocks were prepared. For pathological investigations, $5 \mu \mathrm{m}$ serial sections were cut and stained with hematoxylin and eosin. Images were acquired from standardized regions of liver, kidney, heart and lung using a Spot RT digital camera (Diagnostic Instruments Inc., Sterling Heights, MI) on a Zeiss Axioscop 2 microscope (Carl Zeiss Inc., Thornwood, NY) for image analysis.

\section{Semi-quantitative scoring}

The lesion was evaluated semi-quantitatively by ranking tissue lesion severity. Ranking from 0 to 3 depending on the degree and extent of the alteration as follows: (0) no histopathology changes, (1+) histopathology changes in $<20 \%$ of fields, $(2+)$ histopathology changes in 20 to $60 \%$ of fields, (3+) histopathology changes in $>60 \%$ of fields. This ranking was used by Benli et al. [21], to establish an overall assessment value of the histopathological lesion for studied animal tissues. Five slides were observed from each organ.

\section{Statistical analysis}

All data were analyzed statistically, using a current SPSS statistical package Version 19 and the data presented as Mean \pm Standard Deviation of Means (S.E.M). Comparison between two groups was performed using t-test and $\mathrm{p}$ value was considered statistically significant if $\leq 0.05$.

\section{Results}

\section{Active constitutes}

The total Ajwa polyphenols in Ajwa extract was $283.43 \mathrm{mg} / 100$ gm. The glycosides levels in Ajwa extract were Fructose $37 \mathrm{gm} / 100$ $\mathrm{gm}$ and Glucose $32.5 \mathrm{gm} / 100 \mathrm{gm}$. The content of Flavonoids and Phenolic Compounds were determined as the following mentioned records by HPLC individual phenols analyzed (mg/kg); Rutin $(7.2 \mathrm{mg} /$ $\mathrm{Kg})$; catechin $(8.1 \mathrm{mg} / \mathrm{kg})$ and Caffeic acid $(5.9 \mathrm{mg} / \mathrm{Kg})$. Inhibition of lipid peroxidation was determined by evaluation of two assays Thiobarbituric acid TBA was $1.88 \mathrm{mg} / \mathrm{ml}$ and Diphenylpicrylhydroic DPPH was $3.4 \mathrm{mg} / \mathrm{ml}$.

\section{Blood lead levels}

There was a significant increase in blood lead level of rabbits in the lead acetate alone-treated group. While, rabbits treated with lead acetate plus the Ajwa extract showed a significant decrease in serum lead level compared to lead intoxicated group (Figure 1).

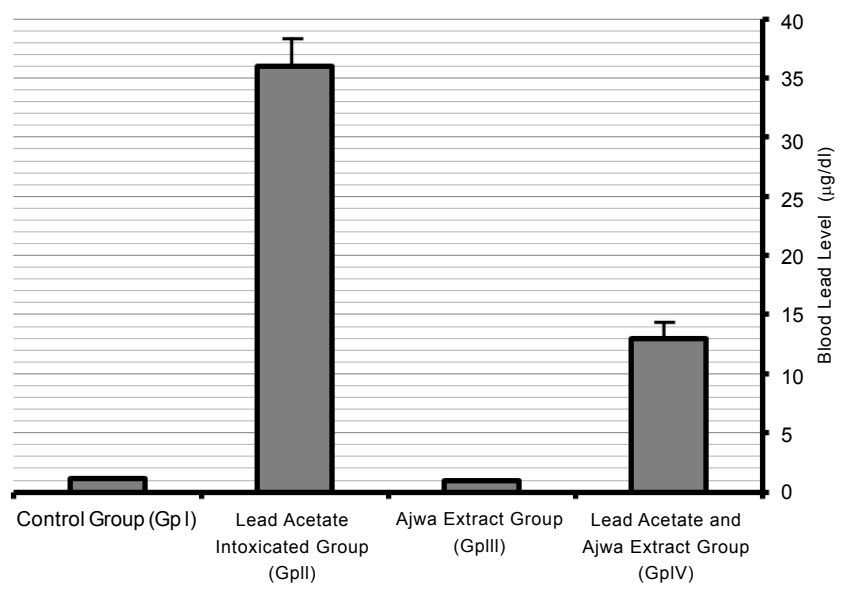

Figure 1: Blood lead levels $(\mu \mathrm{g} / \mathrm{dL})$ in rabbits in different experimental groups. Results are expressed as means \pm S.D of ten rabbit per group and five rabbits in a control group; group IV (lead acetate and Ajwa extract group) significantly different from lead alone treatment group. 
Citation: Ragab AR, Elkablawy MA, Sheik BY, Baraka HN (2013) Antioxidant and Tissue-Protective Studies on Ajwa Extract: Dates from Al Madinah Al-Monwarah, Saudia Arabia. J Environ Anal Toxicol 3:163. doi:10.4172/2161-0525.1000163

Page 4 of 8

\section{Biochemical profile}

The protective action of Ajwa extracts on lead acetate induced hepatic, cardiac and renal toxicities have been summarized in Table 1. The group exposed to lead acetate in drinking water (pretreated with Ajwa extracts) showed the reduced levels of SGOT, SGPT, ALP, TB and $\mathrm{Cr}-\mathrm{U}$ as compared to lead acetate alone intoxicated group. The decreased level in both SGPT and SGOT in (Group IV lead acetate and Ajwa extract group) significantly low from lead alone intoxicated group as in Table 1. Regarding, group III (Ajwa extract alone group), it was noticed a non-significant difference when compared to group I "control group" in all biochemical parameters.

\section{Oxidants-antioxidants profile}

Total antioxidants: Rabbits treated with lead acetate alone showed a significant decrease in serum total antioxidants compared to control $(p<0.05)$ whereas, those treated with the Ajwa extract alone showed a significant increase in total antioxidants. Rabbits received the combined of lead acetate and the extract showed a significant improvement in total antioxidants $(\mathrm{p}<0.05)$ (Figure 2).

Lipid hydroperoxides: The current results revealed that animals

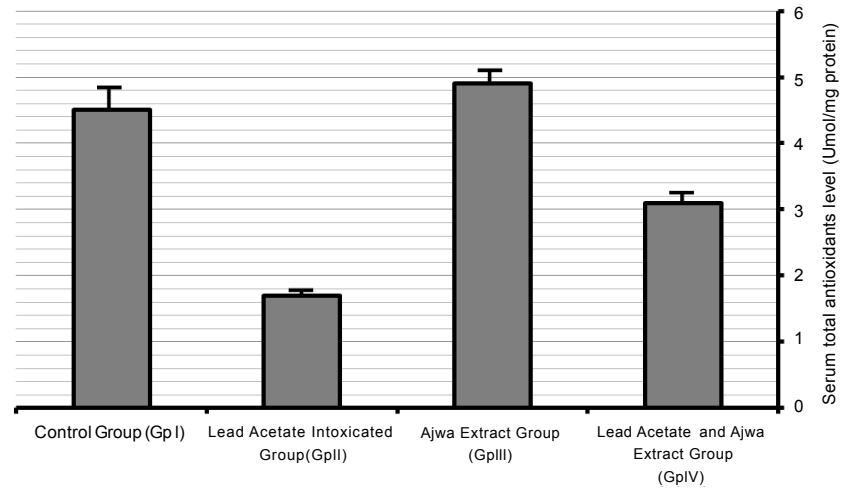

Figure 2: Serum total antioxidants level ( $\mu \mathrm{mol} / \mathrm{mg}$ protein) in control, Ajwa extract alone and in combination with lead acetate-treated rabbits. Results are expressed as means \pm S.D of ten rabbits per group, Ajwa extract groupsignificant different from control group $\mathrm{P}<0.05$ and significantly different lead alone treatment group $\mathrm{P}<0.05$.

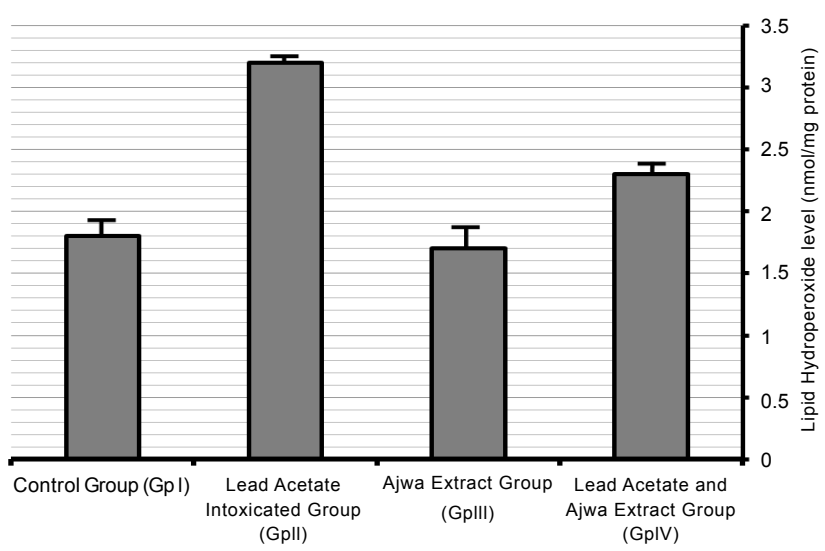

Figure 3: Serum lipid hydroperoxide levels level ( $\mathrm{nmol} / \mathrm{mg}$ protein) in control Ajwa extract alone in combination with lead acetate-treated rabbits. Results are expressed as means \pm SD. of ten rabbits per group, Ajwa extract group I-significantly different from control group $\mathrm{P}<0.05$ II-significantly different from a lead alone treatment group $\mathrm{P}<0.05$.

\begin{tabular}{|l|c|c|c|c|}
\hline Group & $\begin{array}{l}\text { Control } \\
\text { Group }\end{array}$ & $\begin{array}{l}\text { Lead Alone } \\
\text { Intoxicated } \\
\text { Group }\end{array}$ & $\begin{array}{l}\text { Ajwa extract } \\
\text { Alone Group }\end{array}$ & $\begin{array}{l}\text { Ajwa extract } \\
\text { \& lead acetate } \\
\text { group }\end{array}$ \\
\hline $\begin{array}{l}\text { Biochemical } \\
\text { parameters }\end{array}$ & Group I & Group II & Group III & Group IV \\
\hline SGOT (IU/I) & $43.19 \pm 17.86$ & $423.3 \pm 38.12^{*}$ & $41.2 \pm 15.9$ & $144.11 \pm 50.23^{*}$ \\
\hline SGPT (IU/L) & $41.66 \pm 25.11$ & $407.31 \pm 35.5^{*}$ & $42.50 \pm 28.2$ & $210.52 \pm 515.4^{*}$ \\
\hline ALP (IU/L) & $271 \pm 44.22$ & $362 \pm 34.01$ & $272 \pm 41.74$ & $312 \pm 37.3$ \\
\hline TB (mg/dl) & $0.88 \pm 0.13$ & $1.44 \pm 0.30$ & $0.78 \pm 0.22$ & $1.02 \pm 0.09$ \\
\hline Creatinine $(\mu \mathrm{moL} / \mathrm{L})$ & $0.43 \pm 1.02$ & $36.54 \pm 0.41^{*}$ & $0.41 \pm 1.66$ & $29.31 \pm 0.22^{*}$ \\
\hline Urea $(\mathrm{mg} / \mathrm{dL})$ & $5.71 \pm 0.16$ & $15.88 \pm 0.21^{*}$ & $8.01 \pm 0.14$ & $13.57 \pm 0.31$ \\
\hline $\begin{array}{l}\text { Creatine Kinase-MB } \\
(\mathrm{ng} / \mathrm{mL})\end{array}$ & $1.3 \pm 0.2$ & $10.06 \pm 2.1^{*}$ & $0.9 \pm 0.23$ & $6.17 \pm 0.9^{*}$ \\
\hline $\begin{array}{l}\text { C-reactive protein } \\
(\mathrm{mg} / \mathrm{L})\end{array}$ & $0.2 \pm 0.04$ & $6.4 \pm 1.1^{*}$ & $0.3 \pm 0.01$ & $4.3 \pm 0.8^{*}$ \\
\hline $\begin{array}{l}\text { Malonic dialdehyde } \\
(\mu \mathrm{mol} / \mathrm{L})\end{array}$ & $0.4 \pm 0.12$ & $4.1 \pm 1.02^{*}$ & $0.5 \pm 0.5$ & $3.9 \pm 0.9^{*}$ \\
\hline
\end{tabular}

Table 1: Effects of ethanolic extract of Ajwa dates on rabbit serum biochemical parameters lead acetate administrations.

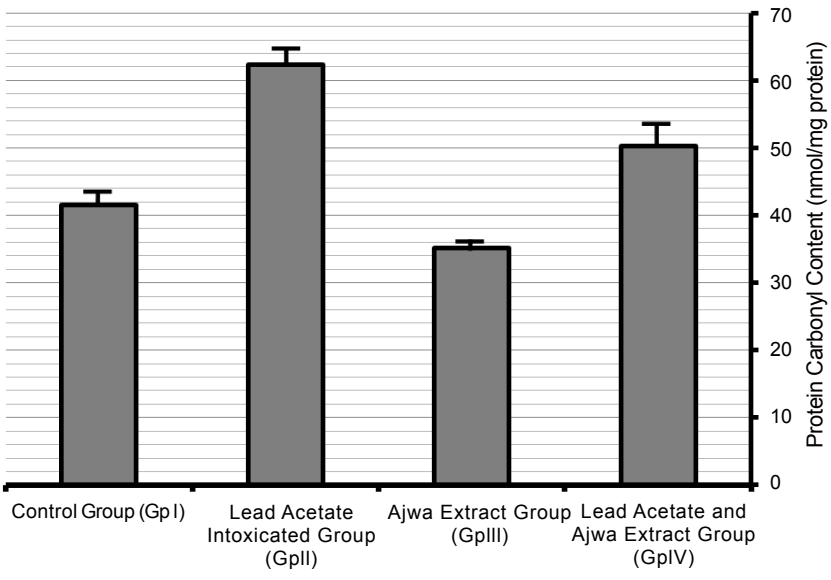

Figure 4: Serum protein carbonyl content (nmol/mg protein) in control, Ajwa extract alone and in combination with lead acetate-treated rabbits. Results are expressed as means $\pm \mathrm{SD}$. of ten rabbits per group, Ajwa extract group I-significantly different from control group $\mathrm{P}<0.05$ II-significantly different from a lead alone treatment group $\mathrm{P}<0.05$. III-significantly different from lead and Ajwa extract group $\mathrm{P}<0.05$

treated with lead acetate alone showed a significant increase in LPO compared to the other experimental groups $(\mathrm{p}<0.05)$. Animals treated with Ajwa Extract were comparable to the control regarding LPO level. Also, the combined of lead acetate plus the extract resulted in a significant decrease $(\mathrm{p}<0.05)$ in LPO resulted from lead exposure, although these levels were still higher than the control group (Figure 3).

Protein carbonyl content: A significant increase in serum protein carbonyl contents was recorded in lead-treated animals $(\mathrm{p}<0.05)$ More than $50 \%$ increase in protein carbonyl content was seen in this group. The level of PCC decreased significantly when Ajwa Extract was administrated to the lead acetate-treated groups $(\mathrm{p}<0.05)$. Moreover, the decrease in PCC was pronounced in the group treated Ajwa Extract alone. Though the level of PCC was significantly reduced with concurrent Ajwa Extract treated rabbits, it did not significantly decrease below the control levels (Figure 4).

Superoxide dismutase: Serum superoxide dismutase showed a significant decrease $(\mathrm{p}<0.05)$ in lead-treated group, and a nonsignificant increase in Ajwa extract treated groups compared to the control group. The combined administration o the extract and lead 


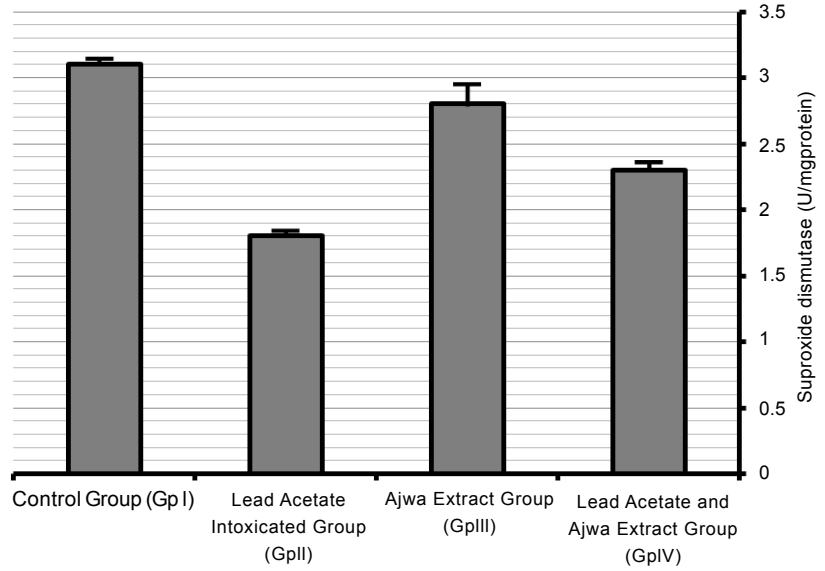

Figure 5: Serum superoxide Dismutase (U/mg protein) in control, Ajwa extract alone and in combination with lead acetate-treated rabbits. Results are expressed as means \pm SD. of ten rabbits per group, Ajwa extract group I-non-significantly different from control group. II-significantly different from a lead alone treatment group $\mathrm{P}<0.05$. III-significantly different from combination of lead and Ajwa extract group $\mathrm{P}<0.05$.

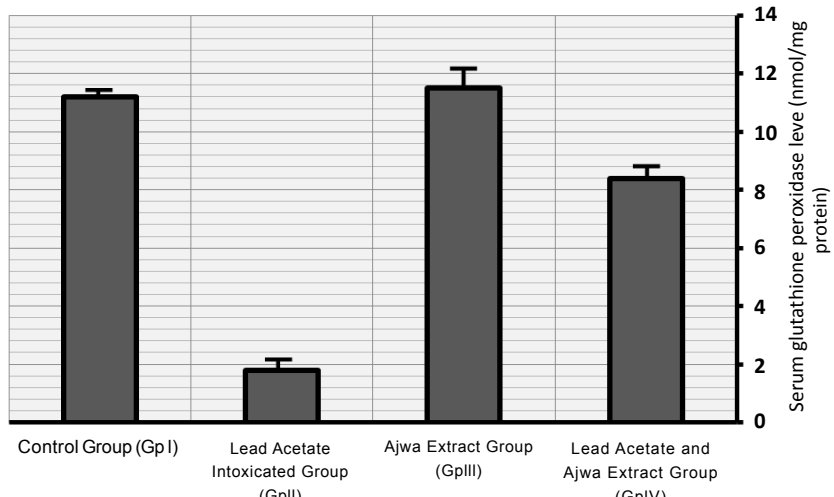

Figure 6: Serum glutathione periodase level (nmol/mg protein) in control, Ajwa extract alone and in combination with lead acetate-treated rabbits. Results are expressed as means $\pm S D$. of ten rabbits per group, Ajwa extract group I-nonsignificantly different from control group $\mathrm{P}<0.05$. II-significantly different from a lead alone treatment group and combined lead acetate-Ajwa extract group $P<0.05$.

resulted in a significant improvement $(\mathrm{p}<0.05)$ in SOD towards the control level although these treatments did not reach SOD normal level except (Figure 5).

Serum glutathione peroxidase level: The current study revealed that GPx was significantly decreased in animals treated with lead acetate alone $(\mathrm{p}<0.05)$. Animals received the extract showed a non significant increase compared to the control group. Whereas, the combined of lead and the extract succeeded to induce a significant improvement $(\mathrm{p}<0.05)$ in GPx, compared to lead alone-treated group, these treatments failed to normalize GPx (Figure 6).

\section{Histopathological profile}

Generally, the histopathological changes from lead acetate-induced injury in the different organs, included vascular congestion, interstitial hemorrhage, cellular degenerations, like cloudy swelling, hydropic degeneration, focal cellular necrosis and inflammatory cellular infiltrate. Administration of Ajwa extract $(300 \mathrm{mg} / \mathrm{kg})$ significantly preserved the almost normal organs' cellular architecture from damaging effects of Lead Acetate. The Histopathological changes are shown in Figures 7-10. The semi-quantitative scoring of histological changes is presented in Table 2 .

\section{Liver histopathological analysis}

A homogeneous normal hepatic lobules and hepatocytes were observed in the control group, and Ajwa extract group (Figure 7a). The most alterations of liver were founded in the second group after lead exposure. The main lesions were marked hepatoportal vascular congestion and disruption of hepatic sinusoids. Hepatocytes showed marked hydropic degeneration, cytoplasmic vacuollations, areas of necrosis with nuclear pyknosis, karyorrhexis and karyolysis, cholestasis and moderate periportal inflammatory cellular infiltrate (Figure $7 \mathrm{c}$ and 7d). The histopathology in the Agwa treated group (Group 4) showed the mild congestion, slight cloudy swelling with minimal focal necrosis (Figure 7b). The semi-quantitative scoring of the liver lesion is shown in Table 2 .

\section{Kidney histopathological analysis}

Kidneys of control group and Ajwa extract group showed normal

\begin{tabular}{|c|c|c|c|c|}
\hline Group & $\begin{array}{l}\text { Control } \\
\text { group }\end{array}$ & $\begin{array}{l}\text { Lead Acetate } \\
\text { Intoxicated } \\
\text { Group }\end{array}$ & $\begin{array}{l}\text { Ajwa } \\
\text { Extract } \\
\text { Group }\end{array}$ & $\begin{array}{l}\text { Lead Acetate } \\
\text { and Ajwa } \\
\text { Extract Group }\end{array}$ \\
\hline $\begin{array}{l}\text { Histopathological } \\
\text { changes }\end{array}$ & Group I & Group II & Group III & Group IV \\
\hline \multicolumn{5}{|l|}{ Liver } \\
\hline $\begin{array}{l}\text { Hepatoportal and Sinusoidal } \\
\text { congestion }\end{array}$ & - & +++ & - & + \\
\hline $\begin{array}{l}\text { Cloudy swelling \& Hydropic } \\
\text { degeneration }\end{array}$ & - & +++ & - & + \\
\hline $\begin{array}{l}\text { Cellular necrosis (Nuclear } \\
\text { pyknosis, karyorrhexis, } \\
\text { karyolysis) }\end{array}$ & - & ++ & - & $-/+$ \\
\hline Inflammatory cellular infiltrate & - & ++ & - & - \\
\hline Cholestasis & - & ++ & - & + \\
\hline \multicolumn{5}{|l|}{ Kidneys } \\
\hline Vascular congestion & - & +++ & - & + \\
\hline Cloudy swelling & - & +++ & - & + \\
\hline $\begin{array}{l}\text { Obliteration of bowman's } \\
\text { capsule }\end{array}$ & - & ++ & - & - \\
\hline $\begin{array}{l}\text { Interstitial and tubular } \\
\text { hemorrhage }\end{array}$ & - & ++ & - & - \\
\hline Focal tubular necrosis & - & ++ & - & - \\
\hline \multicolumn{5}{|l|}{ Heart } \\
\hline Vascular congestion & - & ++ & - & $-/+$ \\
\hline $\begin{array}{l}\text { Cardiac muscle, cloudy } \\
\text { swelling and loss of striation }\end{array}$ & - & ++ & - & + \\
\hline Cardiac muscle necrosis & - & ++ & - & - \\
\hline \multicolumn{5}{|l|}{ Lungs } \\
\hline $\begin{array}{l}\text { Congestion of alveolar } \\
\text { capillaries }\end{array}$ & - & +++ & - & + \\
\hline $\begin{array}{l}\text { Edema \&Thickening of } \\
\text { alveolar wall }\end{array}$ & - & +++ & - & + \\
\hline $\begin{array}{l}\text { Alveolar edema (pink } \\
\text { coagulum in lumen) }\end{array}$ & - & + & - & - \\
\hline $\begin{array}{l}\text { Alveolar Inflammatory cellular } \\
\text { infiltrate }\end{array}$ & - & +++ & - & $-/+$ \\
\hline Alveolar wall destruction & - & ++ & - & - \\
\hline
\end{tabular}

Table 2: Histopathological scoring showing the protective effects of ethanolic extract of Ajwa Extract on rabbit organs after Lead Acetate Administration compared to other groups. 

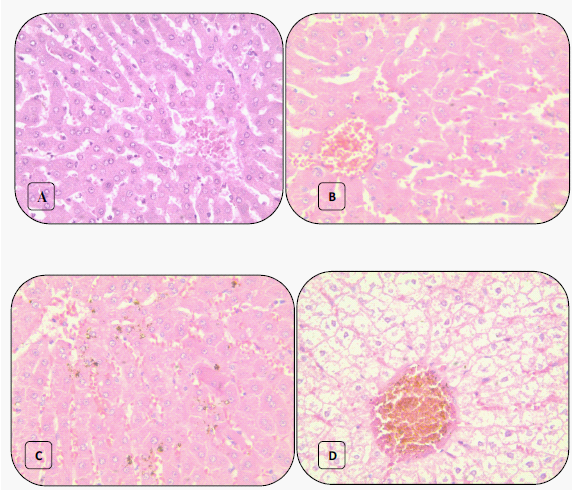

Figure 7: Histopathological changes in liver from (a) control and Ajwa extract groups showing normal hepatic lobule and hepatocytes. (b) Combined Ajwa extract-lead intoxicated group showing mild central vein congestion and cloudy swelling of hepatocytes. (c and d) Lead intoxicated group without treatmen showed(c) marked cloudy swelling of hepatocytes, sinusoidal congestion and cholestasis, (d) marked central vein congestion, hydropic degeneration and vacuolation of hepatocytes. Many hepatocytes show signs of necrosis (pyknosis, kariorrhexis and karyolysis) ( $\mathrm{H}$ and $\mathrm{E}$ stain, 40x).
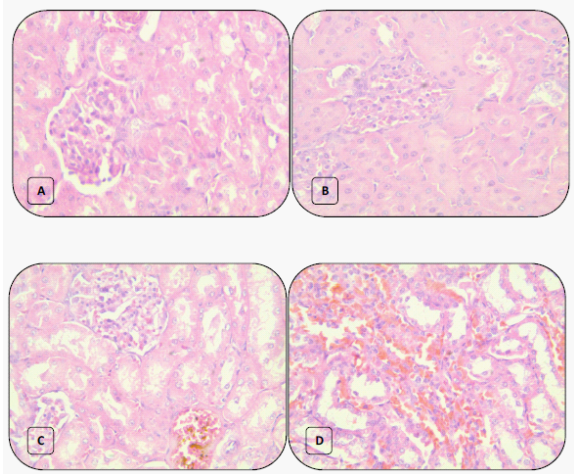

Figure 8: Histopathological changes in kidney from (a) control and Ajwa extract groups showing normal glomerulous and renal tubules. (b) Combined Ajwa extract-lead intoxicated group showing cloudy swelling of renal tubules and narrowing of bowman's capsule. (c and d) Lead intoxicated group without treatment showed (c) marked vascular congestion, cloudy swelling and hydropic degeneration of renal tubules, obliteration of bowman's capsule. Many tubules show signs of necrosis (pyknosis, kariorrhexis and karyolysis), (d) marked interstitial hemorrhage and tubular necrosis ( $\mathrm{H}$ and $\mathrm{E}$ stain, 40x).

appearance of glomerulai and renal tubules (Figure 8a). After lead exposure, renal tissues showed the most conspicuous alterations. Renal vascular congestion, focal tubular and interstitial hemorrhages were observed. Cloudy swelling, tubular narrowing and focal tubular necrosis were also found (Figure $8 \mathrm{c}$ and $8 \mathrm{~d}$ ). Less frequently, cloudy swelling in tubules was seen in Agwa treated group (Group 4) (Figure $8 \mathrm{~b})$. The semi-quantitative scoring of the kidney lesion is shown in Table 2.

\section{Heart histopathological analysis}

Heart of control and Ajwa extract groups showed normal appearance of cardiac muscles and blood vessels (Figure 9a). After lead exposure, mild to moderate cloudy swelling in cardiac muscles, loss of muscular striations and vascular congestion were observed (Figure 9c and 9d). Less frequently, minimal cloudy swelling in cardiac muscles was seen in Agwa treated group (Group 4) (Figure 9b). The semiquantitative scoring of the heart lesion is shown in Table 2.

\section{Lung histopathological analysis}

Lungs of control and Ajwa extract groups showed normal appearance of alveolar capillaries, alveolar walls and alveoli (Figure 10a). After lead exposure, lung tissues showed marked alterations. Marked alveolar capillaries congestion, alveolar wall thickening, pink coagulum in the alveoli, marked alveolar inflammatory cellular infiltrates, moderate alveolar walls destruction and emphysematous changes were observed (Figure 10c and 10d). Less frequently, mild alveolar capillaries congestion and alveolar wall thickening with mild inflammatory cellular exudates were seen in Agwa treated group (Group 4) (Figure 10b). The semi-quantitative scoring of the lung lesion is shown in Table 2.

\section{Discussion}

Lead is known to cause oxidative damage in various tissues by bringing about imbalance in the generation and removal of reactive oxygen species. Although the exact mechanisms by which lead induces
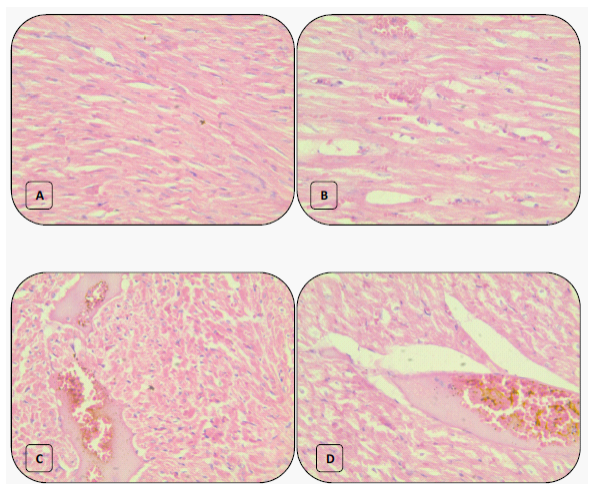

Figure 9: Histopathological changes in heart from (a) control and Ajwa extract groups showing normal cardiac muscles. (b) Combined Ajwa extract-lead intoxicated group showing mild congestion and cloudy swelling with loss of muscle striations. (c and d) Lead intoxicated group without treatment showed (c) marked vascular congestion and interstitial hemorrhage, (d) cardiac muscles signs of necrosis (pyknosis, kariorrhexis and karyolysis) ( $H$ and $E$ stain, 40x).
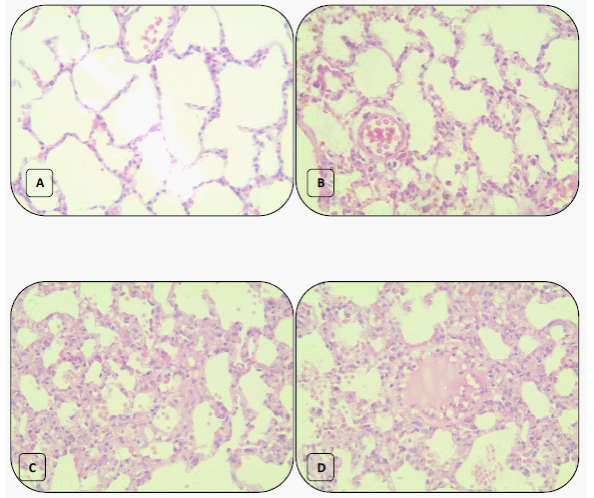

Figure 10: Histopathological changes in lung tissue from (a) control and Ajwa extract groups showing normal alveolar cappilaries, alveolai and alveolar walls. (b) Combined Ajwa extract-lead intoxicated group showing mild alveolar cappilary congestion, thickening of alveolar walls, mild alveolar Inflammatory cellular infiltrate. (c and d) Lead intoxicated group without treatment showed marked alveolar capillaries congestion, alveolar wall thickening, pink coagulum in the alveoli, marked alveolar inflammatory cellular infiltrates, moderate alveolar walls destruction and emphysematous changes were observed $(\mathrm{H}$ and $\mathrm{E}$ stain, 40x). 
oxidative stress in various tissues are not completely understood, evidences indicate that multiple mechanisms may be involved. $[4,5,22,23]$.

Regarding liver function test in the present study (Table 1), the biochemical profile showed marked increase in serum SGOT, SGPT, $\mathrm{ALP}$ and TB in the lead acetate intoxicated group. These results are due to the toxic oxidative stress of lead acetate on liver cells as shown in the histopathological results. This is in agreement with the results obtained by many investigators $[7,22-24]$. The detected significant reduction in the serum enzymes' level by Ajwa extract could be attributed to a decrease in the lipid peroxidation of hepatocellular membrane induced by the Lead Acetate. Also, it may be due to the accelerated regeneration/ repairing of damaged hepatocytes. A similar conclusion was clarified by Saafi et al. and Kilikdar et al. [10,22].

On the same aspect, and with respect to the biochemical renal parameters' profile, blood urea and creatinine were increased in the lead acetate intoxicated group, and these differences were statistically significant. Same results were reported by Sujath et al. in rats [23]. The increase in these substances pointed to the reported pathological alterations in the kidney. In the Ajwa dates treated group a decrease in creatinine and urea levels were recorded in compare to non treated group, but it does not reach the significant level. These results clarify a positive role of Agwa in kidney protection from lead toxicity.

For biochemical myocardial parameters profile, Creatinine kinase$\mathrm{MB}, \mathrm{C}$-reactive protein and Malonic dialdehyde were significantly elevated in the lead acetate intoxicated group compared to control. Also, these differences were statistically significant in comparison to combined lead acetate-Ajwa extract treated group. A similar conclusion was reported by Mohammad et al. [25]. The increased cardiac markers could be directed to the reported pathological degeneration and necrosis in the myocardium, as these biochemical and pathological alterations were markedly minimized in the Ajwa extract treated group compared to non treated lead intoxicated group.

In the current study, lead produces the oxidative damage in various organs. It is widely accepted that lead causes lipid peroxidation through generating the release of reactive oxygen species (ROS) which damage the mitochondrial and cytoplasmic membranes causing more severe oxidative damage in the tissues and consequently, releasing lipid hydroperoxides into circulation [4]. Also, Protein modifications elicited by direct oxidative attack lead to the formation of protein carbonyl derivatives and protein carbonyl content (PCC) [26].

The present study showed that lead acetate exposure in drinking water for 14 days resulted in severe oxidative stress. There was increased in serum lipid hydroperoxide and protein carbonyl content in lead intoxicated group and decrease in total antioxidants and antioxidant enzymes (SOD and GPX). These observations confirm the findings of several studies, which reported alterations in antioxidant enzyme activities both in animals and humans exposed to lead. Although they suggest a possible role of oxidative stress in the pathophysiology of lead toxicity, it is not clear whether the changes in serum antioxidant enzymes are the cause of oxidative damage or a consequence of it. [4,27-29].

Our results regarding antioxidants level showed a significant decrease in the activities of superoxide dismutase, glutathione peroxidase and total antioxidants level in lead intoxicated group which showed a significant increase in blood lead levels (BLL) compared to other groups. These results are in agreement with the previous studies which reported antioxidants exhaustion in the defense system against the reactive oxygen species produced after exposure to lead. This confirms a role of lead acetate in inducing depletion of antioxidants $[4,27,30]$.

On the other hand, the lead intoxicated group treated with Ajwa extract showed significant minimization of lead induced changes in lipid hydroperoxides and antioxidant enzyme levels. Also, administration of ethanol extract of Ajwa significantly increased the serum antioxidant enzymes. These results could be explained by the protective role of Ajwa extract which significantly decreased the blood lead levels (BLL) compared to non treated lead intoxicated group. This implies the possible chelating effect of Ajwa extract in addition to its role as a natural antioxidant, antimutagenic and immune system stimulator. However, this property of Ajwa extract requires further study $[4,10,19,31]$.

The current histopathological evaluation showed that liver and kidneys were the principal target organs for lead toxicity then cardiac muscles and lungs. These findings agreed with those reported by many investigators [21-25]. The results showed marked vascular congestion, interstitial hemorrhage, monocellular infiltrates cellular degeneration and necrosis with different degrees in different organs of lead acetate intoxicated group. The pathomorphological lesions reported in liver were attributed to the action of lead on hepatic glycogen, DNA content and ability to incorporate amino acids into protein $[21,24,32]$. While, the pathological changes due to lead toxicity in kidneys were attributed by some investigators to the accumulation of lead-protein complex, which causes discernible changes in proximal tubular linings of cells $[23,24]$.

The present histopathological results of Agwa extract treated lead intoxicated group showed mild congestion and slight focal cellular degeneration. These results validate the reported ameliorative and protective effects of Agwa dates extract against the toxic effects of lead acetate in our biochemical results. These protective effects could be attributed to the significant amounts of polyphenolic and flavonoid compounds present in the Agwa dates extract. These antioxidant compounds could have played a major role in scavenging the reactive oxygen species induced by lead acetate in the serum $[10,22,33]$.

\section{Conclusion and Recommendations}

This study has shown that Ajwa extract had significant antioxidant activity and caused a significant reversal of the lead-induced changes in the oxidative biomarkers in serum. Observed changes could be due to the different polyphenols, flavonoids, and flavones present in the extract. The results prove for the first time that $\mathrm{Al}$ Madinah Ajwa extract has a variable tissue protective effect via a free radical scavenging and antioxidant properties. The conclusion of present study augments the increased interest among phytotherapy researchers to use medicinal plants with antioxidant activity for protection against heavy metal toxicity. Also, it could provide a scientific cause for the conventional use of Ajwa extract in lead poisoning conditions as a nutritional protocol of management. Further studies should be carried out to determine the value of the accurate preventive and therapeutic protocol offered by Ajwa extract.

\section{Acknowledgment}

The authors are indebted to Prof. Dr. Ahmed Mohammaden from Biochemistry Department-Taibah University- Al Madinah Al-Monawarah, for his time in carrying out biochemical laboratory profile for studied animals and also to Mr. Wael Barakate 
Citation: Ragab AR, Elkablawy MA, Sheik BY, Baraka HN (2013) Antioxidant and Tissue-Protective Studies on Ajwa Extract: Dates from Al Madinah Al-Monwarah, Saudia Arabia. J Environ Anal Toxicol 3:163. doi:10.4172/2161-0525.1000163

Page 8 of 8

and Mr. Mohamed Abd Al Samaed, for providing their hard efforts in carrying out animal house care and some laboratory work duties.

\section{Authors contributions}

AR carried out the laboratory studies, collection of plant materials, helped in analysis of data and preparation of manuscript, analysis and interpretation of the data. MA helped in animal experiments, laboratory studies, preparation of manuscript and interpretation of the data. BS revising the manuscript and interpretation of data. $\mathrm{HN}$ carried out the extraction of Ajwa extract.

\section{References}

1. Manton WI, Angle CR, Stanek KL, Reese YR, Kuehnemann TJ (2000) Acquisition and retention of lead by young children. Environ Res 82: 60-80.

2. Georing PL (1993) Lead-protein interaction as a basis for lead toxicity Neurotoxicol 14: 45-60

3. Hsu CP, Guo LY (2002) Antioxidant nutrients and lead toxicity. Toxicology 180 33-44

4. Patrick L (2006) Lead toxicity part II: the role of free radical damage and the use of antioxidants in the pathology and treatment of lead toxicity. Altern Med Rev 11: 114-127

5. El-Nekeety AA, El-Kady AA, Soliman MS, Hassan NS, Abdel-Wahhab MA (2009) Protective effect of Aquilegia vulgaris (L.) against lead acetate-induced oxidative stress in rats. Food Chem Toxicol 47: 2209-2215.

6. Xu Y, Li G, Han C, Sun L, Zhao R, et al. (2005) Protective effects of Hippophae rhamnoides $\mathrm{L}$. juice on lead-induced neurotoxicity in mice. Biol Pharm Bull 28 490-494

7. Patra RC, Swarup D, Dwivedi SK (2001) Antioxidant effects of alpha tocopherol, ascorbic acid and L-methionine on lead induced oxidative stress to the liver kidney and brain in rats. Toxicology 162: 81-88.

8. Shahadi F, Naczk M (2004) Phenolics in Food and Nutraceuticals. CRC Press LLC.

9. Aisha AFA, Nassar ZD, Siddique MJ, Abu-Salah KM, Alrokayan SA, et al. (2011) Evaluation of antiangiogenic, cytotoxic and antioxidant effects of Syzgium aromaticum L.extracts. Asian J Biol Sci 4: 282-290.

10. Saafi EB, Louedi M, Elfeki A, Zakhama A, Najjar MF, et al. (2011) Protective effect of date palm fruit extract (Phoenix dactlifera $L$ ) on dimethoate inducedoxidative stress in rat liver. Exp Toxicol Pathol 63: 433-441.

11. Al-Shahib W, Marshall RJ (2003) The fruit of date palm: Its possible use as the best food for the future? Int J Food Sci Nutr 54: 247-259.

12. Hasan NS, Amon ZH, Nor Al, Mokhtarrudin N, Esa NM, et al. (2010) Nutritiona composition and in vitro evaluation of the antioxidants propertiest of various dates extracts (Phoenix dactylifera L.) from Libya. Asian J Clin Nutr 2: 208-214.

13. Mansouri A, Embarek G, Kokkalou ES, Kefalas PS (2005) Phenolic Profile and Antioxidant Activity of Alderian Ripe Date Palm Fruit (Phoenix dactylifera). Food Chemistery 89: 411-420.

14. Miller CJ, Dunn EV, Hashim IB (2003) The Glycaemic Index of Dates and Date/ yoghurt Mixed Meals. Are Dates 'the Candy that Grows on Trees'?. Eur J Clin Nutr 57: 427-430

15. Singh RP, Murthy CKN, Jayaprasha GK (2002) Studies on the Antioxidant Activity of Pomegranate (Punica granatum) Peel and Seed Extracts Using in Vitro Models. J Agric Food Chem 50: 81-86.

16. Negi PS, Jayaparakasha GK, Jena BS (2003) Antioxidant and Antimutagenic Activities of Pomegranate Peel Extracts. Food Chemistry 80: 393-397.

17. Association of official Analytical Chemists (AOAC) (1995) Official Methods of Analysis. (16thedn), Arlington: AOAC

18. Lunn G (2000) HPLC Methods for Pharmaceutical Analysis. Interscience Publication, New York.
19. Garcia-Alonso M, Pascual-Tersa S, Santos-Buelga C, Rivas-Gonazlo JC (2004) Evaluation of the Antioxidant Properties of Fruits. Food Chemistry 84: 13-18.

20. Azar A, Trochimowicz HJ, Maxfield ME (1973) Review of lead studies in animals carried out at Haskell Laboratory: Two year feeding study and response to hemorrhage study. International Symposium. Environmental Health Aspects of Lead 199-210.

21. Benli ACK, Koksal G, Ozkul A (2008) Sublethal ammonia exposure of Nile tilapia (Oreochromis niloticus L.): Effects on gill, liver and kidney histology. Chemosphere 72: 1355-1358.

22. Kilikdar D, Mukherjee D, Mitra E, Ghosh AK, Basu A, et al. (2011) Protective effect of aqueous garlic extract against lead-induced hepatic injury in rats. Indian J Exp Biol 49: 498-510.

23. Sujath K, Srilatha $\mathrm{CH}$, Anjaneyulu Y, Amaravathi P (2011) Lead acetate induced nephrotoxicity in wistar albino rats. A pathological, immunohistochemical and ultrastructural studies. Int J Pharm Bio Sci 2

24. Suradkar SG, Vihol PD, Patel JH, Ghodasara DJ, Joshi BP, et al. (2010) PathoMorphological changes in tissues of wistar rats by exposure of Lead acetate. Veterinary World 3: 82-84.

25. Mohammad A, Valiollah DR, Somayeh H, Soleiman M, Akbar HM (2011) The Role of Exercising and Curcumin on the Treatment of lead-induced Cardiotoxicity in Rats. Iranian Journal of Health and Physical Activity 2: 1-5.

26. Shacter E (2000) Quantification and significance of protein oxidation in biological samples. Drug Metab Rev 32: 307-326.

27. Bokara KK, Blaylock I, Denise SB, Bettaiya R, Rajanna S, et al. (2009) Influence of lead acetate on glutathione and its related enzymes in different regions of rat brain. J Appl Toxicol 29: 452-458.

28. El-Nekeety AA, El-Kady AA, Soliman MS, Hassan NS, Abdel-Wahhab MA (2009) Protective effect of Aquilegia vulgaris (L.) against lead acetate-induced oxidative stress in rats. Food Chem Toxicol 47: 2209-2215.

29. Sugawara E, Nakamura K, Miyake T, Fukumura A, Seki Y (1991) Lipid peroxidation and concentration of glutathione in erythrocytes from workers exposed to lead. Br J Ind Med 48: 239-242.

30. Neal R, Cooper K, Kellogg G, Gurer H, Ercal N (1999) Effects of some sulfurcontaining antioxidants on lead-exposed lenses. Free Radic Biol Med 26: 239 243.

31. Rock W, Rosenblat M, Borochov-Neori H, Volkova N, Judeinstein S, et al. (2009) Effects of date (Phoenix dactylifera L., Medjool or Hallawi Variety) consumption by healthy subjects on serum glucose and lipid levels and on serum oxidative status: A pilot study. J Agric Food Chem 57: 8010-8017.

32. Barratt CL, Davies AG, Bansal MR, Williams ME (1989) The effects of lead on the male rat reproductive system. Andrologia 21: 161-166.

33. Gurer H, Ercal N (2000) Can antioxidants be beneficial in the treatment of lead poisoning? Free Radic Biol Med 29: 927-945. 